\section{Late accretion history \\ of the terrestrial planets inferred from platinum stable isotopes}

\section{J.B. Creech ${ }^{1,2 *}$, J.A. Baker ${ }^{3}$, M.R. Handler ${ }^{4}$} J.-P. Lorand ${ }^{5}$, M. Storey ${ }^{6}$, A.N. Wainwright ${ }^{7}$, A. Luguet $^{8}$, F. Moynier ${ }^{2,9}$, M. Bizzarro ${ }^{1}$

\section{Abstract}

Late accretion of chondritic material to differentiated planetary bodies is thought to have been common in the early solar system. However, the timing and scale of admixing this material to terrestrial planets are poorly constrained. Using platinum (Pt) stable isotope data in a range of solar system bodies, we show that Earth's post-Archean mantle has chondritic ${ }^{198} \mathrm{Pt} / 194 \mathrm{Pt}$, consistent with addition of a chondritic late-veneer after core formation. Conversely, terrestrial Archean samples record non-chondritic, heavy, ${ }^{198} \mathrm{Pt} / 194 \mathrm{Pt}$, indicating preservation of early mantle components that escaped complete mixing with the late-veneer. These data suggest admixing of $\leq 50 \%$ of the eventual full late-veneer inventory. Such effective mixing within Earth's mantle by $3.85 \mathrm{Ga}$ is most consistent with modern-style plate tectonics.

Received 7 September 2016 | Accepted 19 October 2016 | Published 8 November 2016

Centre for Star and Planet Formation, Natural History Museum of Denmark, University of Copenhagen Øster Voldgade 5-7, 1350 Copenhagen, Denmark

Institut de Physique du Globe de Paris, Université Sorbonne Paris Cité, Université Paris Diderot, 1 Rue Jussieu, 75328 Paris Cedex 05, France

Corresponding author (email: creech@ipgp.fr)

School of Environment, The University of Auckland, Private Bag 92019, Auckland, New Zealand

School of Geography, Environment and Earth Sciences, Victoria University of Wellington, PO Box 600 Wellington, New Zealand

Laboratoire de Planétologie et Géodynamique de Nantes, CNRS UMR 6112, Université de Nantes, 2 Rue de la Houssinière, BP 92208, 44322 Nantes Cedex 3, France

Quadlab, Natural History Museum of Denmark, University of Copenhagen, Øster Voldgade 5-7, 1350 Copenhagen, Denmark

Laboratoire G-Time, Université Libre de Bruxelles, 50 Avenue F.D. Roosevelt, 1050 Brussels, Belgium Steinmann Institut für Geologie Mineralogie und Paläontologie, Rheinische Friedrich-WilhemsUniversität, 53115 Bonn, Germany

9. Institut Universitaire de France, 75005 Paris, France
Letter

Cratering of the lunar surface provides evidence for a cataclysmic late bombardment event that culminated 3.9 Gyr ago, possibly associated with the disturbance of the planetesimal disk triggered by migration of the gas giants (Gomes et al. 2005). The late-veneer refers to the sum of material added to Earth's mantle after the final episode of core formation, which is thought to have comprised a contribution of $\sim 0.5 \mathrm{wt}$. \% of Earth's mass $\left(\sim 2 \times 10^{22} \mathrm{~kg}\right)$ from chondritic material (Walker, 2009). Addition of this material can explain the elevated mantle HSE abundances and their broadly chondritic relative proportions (Lorand et al., 2008; Walker, 2009), and provide a mechanism for the delivery of volatiles to Earth (Owen and Bar-Nun, 1995). Alternatively, due to changes in partitioning behaviour of HSE under different physical conditions, the elevated HSE abundances in Earth's mantle may be the result of core formation at high-temperatures and -pressures (Mann et al., 2012). The late-veneer hypothesis is apparently supported by the existence of small enrichments in ${ }^{182} \mathrm{~W}$ in the early Archean terrestria rock record (Willbold et al, 2011, 2015; Touboul et al., 2014). However, the timing and scale of veneering of the early Earth are poorly constrained and the origin of these Archean enrichments is controversial (e.g., Rizo et al., 2016). Moreover, the utility of the ${ }^{182} \mathrm{~W}$ tracer is limited to young planetary bodies, as late accretion signatures may be overprinted from radiogenic ingrowth from the decay of the short-lived ${ }^{182} \mathrm{Hf}$ nuclide $\left(\mathrm{t}_{1 / 2}=8.9 \mathrm{Myr}\right)$ in early-formed bodies.

We developed the techniques for the investigation of natural stable isotope fractionation of the HSE platinum (Creech et al., 2013, 2014), which is a novel tool to investigate the late accretion history of the terrestrial planets. Stable isotopic fractionations relating to metal-silicate differentiation have been reported in several stable isotope systems, e.g., Si (Young et al., 2015), Mo (Hin et al., 2013, Burkhardt et al., 2014), Zn (Mahan et al., 2017). The metal-silicate partitioning of $\mathrm{Pt}$ is much greater than for these other elements and, combined with the differences in oxidation state and bonding environment between mantle silicates and the Fe-Ni metallic core, Pt has the potential for significant stable isotope fractionation related to metal-silicate partitioning and core formation. Theory predicts that the heavy isotopes of an element will tend to be concentrated in the most oxidised component of a system (Schauble, 2004), which is supported by experimental data for Mo (Hin et al., 2013), and therefore heavy Pt stable isotopes might be expected in oxidised silicate mantles of differentiated bodies. Here, we present $\mathrm{Pt}$ stable isotope data for major solar system reservoirs, including chondrites, achondrites and Earth, to trace late accretion processes.

Platinum isotope data are expressed in $\delta^{198} \mathrm{Pt}$ notation, which reports per mil (\%o) deviations in the ${ }^{198} \mathrm{Pt} /{ }^{194} \mathrm{Pt}$ ratio relative to a standard, corrected for instrumental fractionation using a ${ }^{196} \mathrm{Pt}-{ }^{198} \mathrm{Pt}$ double spike. The double-spike correction assumes that there are no mass-independent fractionation effects arising from nucleosynthetic processes. Nucleosynthetic variability has been documented in relatively low mass siderophile elements, such as Mo and Ru, with significant nucleosynthetic isotope heterogeneity existing between the various 
classes of chondrites (e.g., Burkhardt et al., 2011; Fischer-Gödde et al., 2015). However, so far no isotopic anomalies have been documented in heavy siderophile elements with masses more comparable to Pt (e.g., Os, Te, Cd; Yokoyama and Walker, 2016). If variations on a similar scale to those in Mo and Ru exist for $\mathrm{Pt}$, we would expect to see large variations in double-spike data corrected assuming mass dependent fractionation, particularly between chondrite groups.

We determined the $\delta^{198} \mathrm{Pt}$ values of chondrites, as these are thought to represent the bulk composition of the solar system and the putative veneering material. Platinum stable isotope compositions of chondrites are identical across groups (ordinary, enstatite and carbonaceous), establishing Pt stable isotope homogeneity amongst primitive solar system bodies. This observation confirms that nucleosynthetic variations in $\mathrm{Pt}$, if present, must be very limited and well within the uncertainties of our measurements. In contrast to enstatite and ordinary chondrites, carbonaceous chondrites contain significant amounts of refractory inclusions, which are known to preserve nucleosynthetic anomalies for a number of elements (Birck, 2004). Combined with the relatively small sample size $(<0.5 \mathrm{~g})$ of many of the carbonaceous chondrites analysed, this may explain the greater variability in this group (see Supplementary Information for further discussion). As such, we use enstatite and ordinary chondrites as well as replicates from a $\sim 15 \mathrm{~g}$ aliquot of the Allende carbonaceous chondrite to define the chondritic $\delta^{198} \mathrm{Pt}=-0.14 \pm 0.03 \%$ o (2 sd).

We investigate the effect of metal-silicate differentiation on Pt stable isotopes using achondrite meteorites. Primitive achondrites sample bodies that have undergone varying degrees of metal-silicate segregation, as reflected by HSE abundances that span a range from $~ 50-1500 \mathrm{ng} \mathrm{g}^{-1}$ (Warren et al., 2006; Rankenburg et al., 2008) which has been interpreted to reflect the early stages of core formation (Warren et al., 2006). The primitive achondrites show increasingly heavy $\delta^{198} \mathrm{Pt}$ from chondritic values to $\geq 0.35 \%$ o heavier than chondrites with decreasing HSE content (Fig. 1). We interpret this to reflect Pt stable isotopic fractionation during core formation, whereby the heavy isotopes of Pt are preferentially retained in the more oxidised silicate part of the body while the light isotopes are concentrated in the metallic core, which is consistent with qualitative predictions based on stable isotope theory (Schauble, 2004) and Mo experimental data (Hin et al., 2013) as described above. Given the leverage of the metallic core, which contains $>99.99 \%$ of the $\mathrm{Pt}$, the greatest fractionation is observed in the most Pt depleted primitive achondrite samples (Fig. 1). However, as these represent relatively small degrees of metal-silicate differentiation, the magnitude of heavy Pt isotope enrichment provides only a minimum constraint on the $\mathrm{Pt}$ stable isotopic fractionation during core formation. In contrast, iron meteorites represent the cores of their respective parent bodies and have very high HSE abundances and chondritic Pt stable isotope composition $\left(\delta^{198} \mathrm{Pt}=-0.19 \pm 0.11\right.$ $\%$; Fig. 1). We note that larger uncertainties in iron meteorite data potentially arise from cosmogenic effects, as discussed in the Supplementary Information.

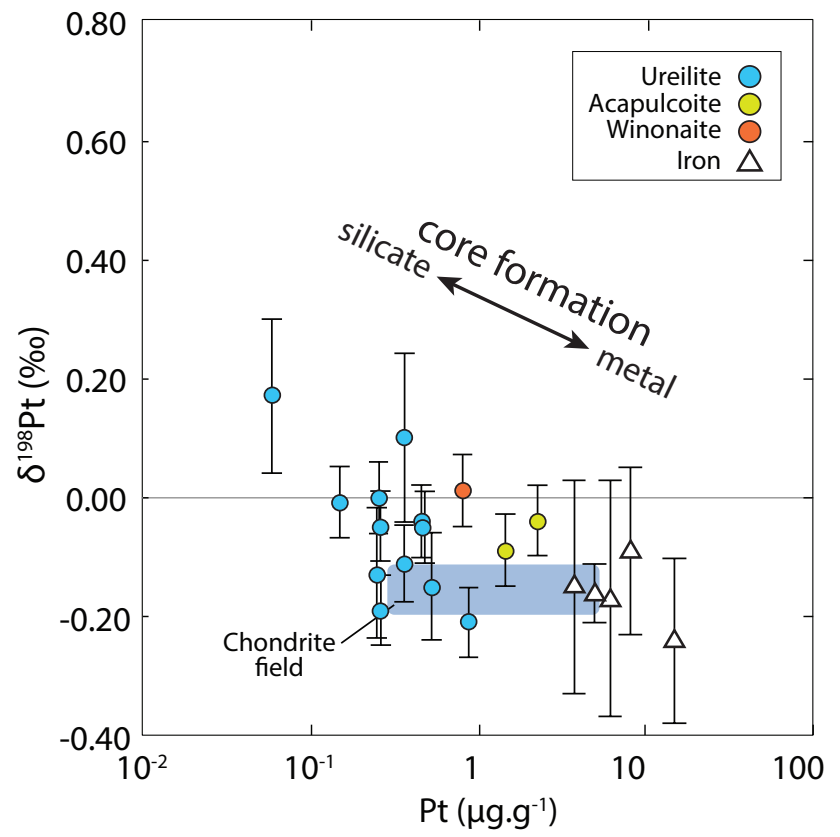

Figure 1 Platinum stable isotopes vs. Pt concentrations in achondrite meteorite samples showing increasingly heavy Pt isotopic compositions corresponding with decreasing Pt concentrations, indicating that heavy Pt isotopes are concentrated in the silicate mantle during metal-silicate differentiation. The shaded field represents the mean and $2 \mathrm{sd}$ of chondrites, as given in the text. Error bars on $\delta^{198} \mathrm{Pt}$ are the 2 sd of combined measurements or the reproducibility of the method as determined by replicate digestions of similar samples, whichever is larger (Supplementary Information). Uncertainties in Pt concentration are negligible on this logarithmic scale. Iron meteorite samples have larger uncertainties in $\delta^{198} \mathrm{Pt}$ owing to cosmogenic effects, which are discussed further in the Supplementary Information. A regression through the ureilite data gives a slope of $-0.108 \%$ per log unit of concentration $\left(r^{2} \sim 0.43\right)$; excluding ALHA81101, the slope is $0.069 \%$ per log unit of concentration, $\left(r^{2} \sim 0.14\right)$.

The post-Archean terrestrial mantle, represented by mantle peridotites sampled from various geological settings and localities (Table S-1), has a mean $\delta^{198} \mathrm{Pt}$ of $-0.10 \pm 0.10 \%$ ( $2 \mathrm{sd}$; Fig. 2 ), which is indistinguishable from the chondritic value. There is some variability amongst post-Archean mantle xenolith samples, possibly reflecting mantle processes such as melt extraction or metasomatism, but the limited range suggests that the Pt stable isotope composition of Earth's convecting mantle has been homogeneous since the Proterozoic. The absence of a heavy Pt stable isotopic signature in Earth's post-Archean mantle suggests that the isotopic signature of core formation on Earth has been overprinted by a late-veneer of chondritic material, although it is not possible to constrain which type of chondrite may have dominated the late accreted material. 


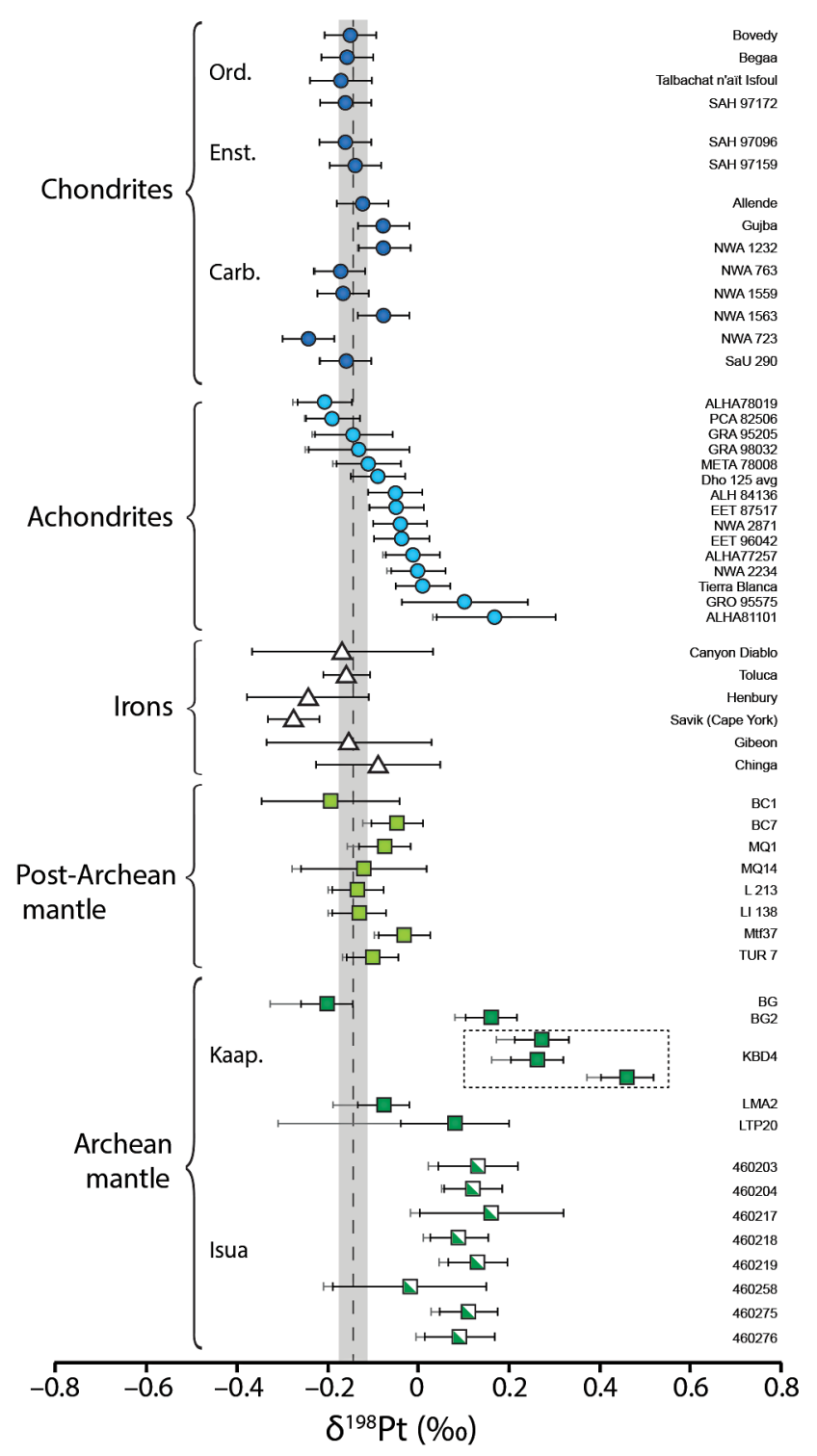

Figure 2 Platinum stable isotope results for terrestrial and meteorite samples. Error bar on $\delta^{198} \mathrm{Pt}$ for NiS digested samples are the $2 \mathrm{sd}$ of combined replicates or the reproducibility of the method as determined by replicate digestions of similar samples, whichever is larger (Supplementary Information). Extended error bars illustrate the additional uncertainty arising from the potential presence of small amounts of analytical blank (further details are given in the Supplementary Information). The dashed vertical line and grey box represent the mean and $2 \mathrm{sd}$ of chondrites as discussed in the text. For one Kaapvaal sample where the variability in replicate digestions exceeded the reproducibility of the technique (interpreted as reflecting real isotopic heterogeneity on the scale of these samples) all three replicates are shown enclosed in a dashed box, where the size of the box represents the $2 \mathrm{sd}$ of the three replicates. Large uncertict Supplementary Information.

In contrast to post-Archean mantle, Archean terrestrial rocks from southern Africa and Greenland have non-chondritic, heavy Pt stable isotopes. The cratonic xenolith suite from southern Africa, sampled from Kaapvaal craton kimberlites, have $\delta^{198} \mathrm{Pt}$ extending to significantly $(\geq 0.5 \%$ o) heavier compositions than chondrites and post-Archean mantle (Fig. 2). Kimberlite-hosted peridotite xenoliths from this area are considered to represent sub-cratonic lithospheric mantle up to 3.6 Ga in age (Griffin et al., 2004), and all five samples have Late Archean Os model ages (Table S-1). While depletions in incompatible PGE (Pd, $\mathrm{Pt}, \mathrm{Re}$; Table S-1) indicate extraction of partial melts, the low Pt concentrations $\left(0.4-2.7 \mathrm{ng} \mathrm{g}^{-1}\right)$ in these samples relative to our post-Archean mantle xenoliths (5.2-7.3 $\mathrm{ng} \mathrm{g}^{-1}$ ) could also be consistent with a smaller late-veneer Pt contribution in the Kaapvaal subcratonic mantle. Variable HSE concentrations in kimberlitehosted xenoliths have been interpreted to represent the sluggish equilibration of Archean mantle with the putative late-veneer (Maier et al., 2012), in keeping with the Pt stable isotopic variability in these samples. We also find that metabasalts and ultramafic schists from the $>3.85$ Ga (Nutman et al., 1997) Isua Supracrustal Belt also have heavy $\delta^{198} \mathrm{Pt}$ (Fig. 2). Given the large degrees of partial melting required to produce the Isua rocks (based on high- $\mathrm{MgO}$ content), the Pt concentrations and isotope compositions of these samples likely reflect their mantle source. Moreover, these samples also preserve ${ }^{142} \mathrm{Nd}$ excesses of up to $\sim 10 \mathrm{ppm}$ from the decay of short-lived ${ }^{146} \mathrm{Sm}\left(\mathrm{t}_{1 / 2} \sim 68-103 \mathrm{Ma}\right)$, indicative of the early differentiation of their source reservoir (Rizo et al., 2013). The heavy Pt stable isotopic compositions observed in these geographically separated Archean rocks from Africa and Greenland are not found in any younger mantle samples analysed thus far. Given the fractionation towards heavier $\delta^{198} \mathrm{Pt}$ in the silicate component during core formation inferred from achondrites, we interpret the heavy $\mathrm{Pt}$ isotopic compositions in these Archean samples as reflecting preservation of a pre-late-veneer signature of Earth's core formation. This is consistent with ${ }^{182} \mathrm{~W}$ data from Isua and other ancient rocks (Willbold et al., 2011, 2015; Touboul et al., 2014), which have also been interpreted to reflect long-term preservation of prelate-veneer mantle that had escaped complete mixing with late-veneer.

Although both sets of Archean samples have lower Pt concentrations than post-Archean samples (Table S-1), Pt is not as depleted as would be expected for pre-late-veneer material under low-pressure and -temperature coreforming conditions. Experimentally determined HSE partition coefficients at 
high-pressures and -temperatures cannot explain mantle abundances by equilibrium core formation alone (Mann et al., 2012). However, if the core formed under these conditions, the Pt depletion in the pre-late-veneer mantle would be significantly reduced (e.g., $\mathrm{Pt} \sim 0.1 \mathrm{ng} \mathrm{g}^{-1}$ in pre-late-veneer mantle as compared with $\mathrm{ca}$. $7 \mathrm{ng} \mathrm{g}^{-1}$ in the primitive upper mantle; Becker et al., 2006), and a combination of high-pressure and -temperature core formation with a chondritic late-veneer can explain both the Pt concentrations and Pt stable isotope data. Mixing calculations modelling the effect of addition of chondritic late-veneer (with $\delta^{198} \mathrm{Pt} \sim-0.14 \%$ o and $1 \mu \mathrm{g} \mathrm{g}^{-1} \mathrm{Pt}$ ) to a hypothetical pre-late-veneer mantle can reproduce our Pt isotope and concentration data for Isua and post-Archean mantle if we assume a pre-late-veneer mantle with $0.14 \mathrm{ng} \mathrm{g}^{-1} \mathrm{Pt}$ (using partition coefficients for core formation at high-pressure and -temperature), Pt isotopic fractionation during core formation of $\sim 4 \%$, and a final amount of late-veneer equating to $0.5 \mathrm{wt} . \%$ of Earth's mass (Fig. 3; Supplementary Information). Based on this, the Pt abundance in Isua samples can be interpreted as reflecting admixing of up to 50 \% of the full complement of late-veneer (Fig. 3), which is consistent with recent ${ }^{182} \mathrm{~W}$ data indicating that the lunar mantle has a marginally greater ${ }^{182} \mathrm{~W}$ enrichment relative to the early Archean terrestrial mantle (Kruijer et al., 2015; Touboul et al., 2015).

The Kaapvaal peridotite xenoliths have approximately half the Pt content of the Isua samples, although the variable Pt concentrations and isotopic compositions likely reflect variable degrees of equilibration with the kimberlite host and/or post-veneer convecting mantle. Thus, the heaviest isotopic composition, defined by multiple digestions of the sample KBD-4 $\left(\delta^{198} \mathrm{Pt}=0.27-0.46 \%\right.$ ), is considered to represent the most pristine pre-late-veneer signature. The heavier $\delta^{198} \mathrm{Pt}$ and lower Pt concentrations of the Kaapvaal mantle xenoliths could indicate that they preserve a more pristine pre-late-veneer signature relative to Isua, which may reflect an older mantle source or, alternatively, spatial heterogeneity. These observations require that progressive admixing of veneering material to Earth's mantle was initiated prior to the formation of the Isua mantle source at $\geq 4.3 \mathrm{Ga}$ based on the ${ }^{146} \mathrm{Sm}-{ }^{142} \mathrm{Nd}$ decay system (Rizo et al., 2013). Accepting an age of $\sim 4.4 \mathrm{Ga}$ for the timing of the Moon-forming impact (Borg et al., 2011), our data suggest that the delivery, admixing, and homogenisation of chondritic, perhaps volatile-rich, material to the early Earth occurred very shortly after magma ocean crystallisation. This requires efficient mixing of the Hadean mantle, which is most easily understood in the framework of modern-style, mobile-lid tectonics rather than a stagnant-lid regime (Debaille et al., 2013). More speculatively, the early delivery of volatile-rich material through impact may have promoted rapid formation of the terrestrial hydrosphere and, hence, assisted hydration of the crust that is required for the inception of plate tectonic processes (O'Neill et al., 2007).
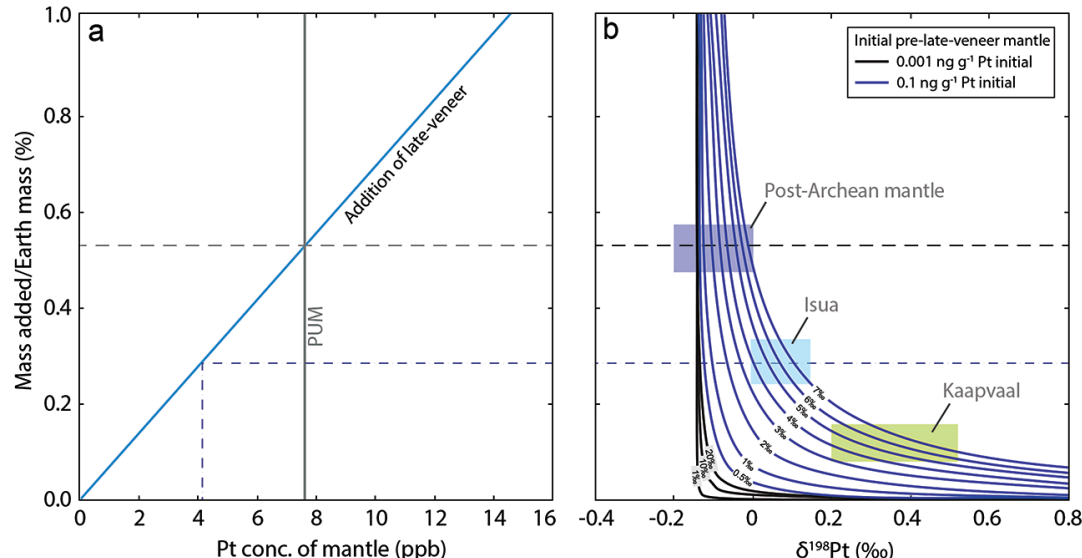

Pt conc. of mantle (ppb)

Figure 3 Model of the effect of addition of chondritic late-veneer on the abundance and isotopic composition of $\mathrm{Pt}$ in the mantle. (a) The calculated mantle concentration of $\mathrm{Pt}$ from the addition of chondrite to the pre-late-veneer mantle. The vertical line represents the Pt concentration of primitive upper mantle (PUM; 7.6 ppb; Becker et al., 2006), and the dashed horizontal line marks the intercept of the mantle concentration with PUM, indicating the amount of late-veneer required to reproduce the $\mathrm{Pt}$ abundance of PUM. (b) The Pt isotopic mantle with tack and blue lines representing mixtures with initial pre-late-veneer mantle Pt mantle, with black and blue lines repres $\mathrm{ng}^{-1}$, relating to core formation at low- or high-

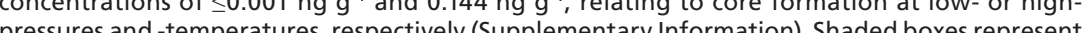
the composition of the post-Archean mantle and inferred composition of the Archean mantle cources of Isua and Kapvat (based on the range of values defined by the sample KBD4 sources of lsua and Kaapvaal (based on the range of values defined by the sample KBD4, was not used to constrain the model, as Pt cone-late-vens during core-formation.

\section{Acknowledgements}

The authors wish to thank Henning Haack for providing the sample Savik, NASA for providing ureilite meteorite samples, Minik Rosing at the Natural History Museum of Denmark and Tod Waight at IGN, Copenhagen University for use of rock powdering facilities, and Rosemary Arts for help in the laboratory. This research was supported by a Royal Society of New Zealand Marsden Grant to $\mathrm{MH}$ and JB and grants from the Danish National Research Foundation (grant number DNRF97) and from the European Research Council (ERC Consolidator grant agreement 616027-STARDUST2ASTEROIDS) to M.B. F.M. acknowledges funding from the European Research Council (ERC Starting grant agreement 637503-Pristine) as well as the financial support of the UnivEarthS Labex program at Sorbonne Paris Cité (ANR-10-LABX-0023 and ANR-11-IDEX-0005-02) and a chaire d'excellence ANR-Idex Sorbonne Paris Cité. AL and AW thank Kevin Burton 
and Geoff Nowell (Earth Science Department, University Durham, UK) for the Os contents and ${ }^{187} \mathrm{Os} /{ }^{188} \mathrm{Os}$ compositions determination of the Kaapvaal cratonic peridotites. All data are available in the main manuscript and Supplementary Information. We also thank Pierre Olivier Foucault and Joel Dyon (IPGP) for producing the image for the graphical abstract.

Editor: Helen Williams

\section{Additional Information}

Supplementary Information accompanies this letter at www.geochemicalperspectivesletters.org/article1710

Reprints and permission information are available online at http://www. geochemicalperspectivesletters.org/copyright-and-permissions

Cite this letter as: Creech, J.B., Baker, J.A., Handler, M.R., Lorand, J.-P., Storey, M., Wainwright, A.N., Luguet, A., Moynier, F., Bizzarro, M. (2017) Late accretion history of the terrestrial planets inferred from platinum stable isotopes. Geochem. Persp. Let. 3, 94-104.

\section{References}

Becker, H., Horan, M.F., Walker, R.J., GaO, S., Lorand, J.-P., Rudnick, R.L. (2006) Highly siderophile element composition of the Earth's primitive upper mantle: Constraints from new data on peridotite massifs and xenoliths. Geochimica et Cosmochimica Acta 70, 4528-4550.

BIRCK, J.L. (2004) An Overview of Isotopic Anomalies in Extraterrestrial Materials and Their Nucleosynthetic Heritage. Reviews in Mineralogy and Geochemistry 55, 25-64.

Borg, L.E., Connelly, J.N., Boyet, M., CARLson, R.W. (2011) Chronological evidence that the Moon is either young or did not have a global magma ocean. Nature 477, 70-72.

Burkhardt, C., Kleine, T., Oberli, F., Pack, A., Bourdon, B., Wieler, R. (2011) Molybdenum isotope anomalies in meteorites: Constraints on solar nebula evolution and origin of the Earth. Earth and Planetary Science Letters 312, 390-400,

BurKhardt, C., Hin, R.C., KLeine, T., Bourdon, B. (2014) Evidence for Mo isotope fractionation in the solar nebula and during planetary differentiation. Earth and Planetary Science Letters 391, 201-211.

Creech, J., BaKer, J., Handler, M., Schiller, M., Bizzarro, M. (2013) Platinum stable isotope ratio measurements by double-spike multiple collector ICPMS. Journal of Analytical Atomic Spectrometry 28, 853-865.

CReech, J.B., BAKeR, J.A., HANDleR, M.R., BizZARro, M. (2014) Platinum stable isotope analysis of geological standard reference materials by double-spike MC-ICPMS. Chemical Geology 363, 293-300.

Debaille, V., O’Neill, C., Brandon, A.D., Haenecour, P., Yin, Q.-Z., Mattielli, N TREIMAN, A.H. (2013) Stagnant-lid tectonics in early Earth revealed by ${ }^{142} \mathrm{Nd}$ variations in late Archean rocks. Earth and Planetary Science Letters 373, 83-92.

Fischer-Gödde, M., BurKhardt, C., KRUiJer, T.S., KLeine, T. (2015) Ru isotope heterogeneity in the solar protoplanetary disk. Geochimica et Cosmochimica Acta 168, 151-171.
Gomes, R., Levison, H.F., Tsiganis, K., MorbiDelLi, A. (2005) Origin of the cataclysmic Late Heavy Bombardment period of the terrestrial planets. Nature 435, 466-469.

Griffin, W.L., Graham, S., O’Reilly, S.Y., PeArSON, N.J. (2004) Lithosphere evolution beneath the Kaapvaal Craton: Re-Os systematics of sulfides in mantle-derived peridotites. Chemical Geology 208, 89-118.

Hin, R.C., BurkhardT, C., Schmidt, M.W., Bourdon, B., Kleine, T. (2013) Experimental evidence for Mo isotope fractionation between metal and silicate liquids. Earth and Planetary Science Letters $379,38-48$.

KRUIJER, T.S., KLeINE, T., FISCHER-GÖDDE, M., SPRUNG, P. (2015) Lunar tungsten isotopic evidence for the late veneer. Nature 520, 534-537.

Lorand, J.-P., Luguet, A., AlARD, O. (2008) Platinum-Group Elements: A New Set of Key Tracers for the Earth's Interior. Elements 4, 247-252.

Mahan, B., Siebert, J., Pringle, E.A., Moynier, F. (2017) Elemental partitioning and isotopic fractionation of $\mathrm{Zn}$ between metal and silicate and geochemical estimation of the $\mathrm{S}$ content of the Earth's core. Geochimica et Cosmochimica Acta 196, 252-270.

Maier, W.D., Peltonen, P., McDonald, I., Barnes, S.J., Barnes, S.-J., Hatton, C., Viljoen, F. (2012) The concentration of platinum-group elements and gold in southern African and Karelian kimberlite-hosted mantle xenoliths: Implications for the noble metal content of the Earth's mantle. Chemical Geology 302-303, 119-135.

Mann, U., Frost, D.J., Rubie, D.C., Becker, H., Audétat, A. (2012) Partitioning of Ru, Rh, Pd, $\mathrm{Re}$, Ir and Pt between liquid metal and silicate at high pressures and high temperatures Implications for the origin of highly siderophile element concentrations in the Earth's mantle. Geochimica et Cosmochimica Acta 84, 593-613.

NutMan, A.P., Mojzsis, S.J., Friend, C.R.L. (1997) Recognition of $>3850$ Ma water-lain sediments in West Greenland and their significance for the early Archaean Earth. Geochimica et Cosmochimica Acta 61, 2475-2484

O'Neill, C., JellineK, A.M., LenARdic, A. (2007) Conditions for the onset of plate tectonics on terrestrial planets and moons. Earth and Planetary Science Letters 261, 20-32.

OWEN, T., BAR-Nun, A. (1995) Comets, impacts, and atmospheres. Icarus 116, 215-226.

Rankenburg, K., Humayun, M., Brandon, A.D., Herrin, J.S. (2008) Highly siderophile elements in ureilites. Geochimica et Cosmochimica Acta 72, 4642-4659.

Rizo, H., Boyet, M., Blichert-Toft, J., Rosing, M.T. (2013) Early mantle dynamics inferred from ${ }^{142} \mathrm{Nd}$ variations in Archean rocks from southwest Greenland. Earth and Planetary Science Letters 377, 324-335.

Rizo, H., Walker, R.J., Carlson, R.W., Touboul, M., Horan, M.F., Puchtel, I.S., Boyet, M., RosING, M.T. (2016) Early Earth differentiation investigated through ${ }^{142} \mathrm{Nd},{ }^{182} \mathrm{~W}$, and highly siderophile element abundances in samples from Isua, Greenland. Geochimica et Cosmochimica Acta 175, 319-336.

Schauble, E.A. (2004) Applying Stable Isotope Fractionation Theory to New Systems. Reviews in Mineralogy and Geochemistry 55, 65-111.

Touboul, M., LiU, J., O’Neil, J., Puchtel, I.S., WALKeR, R.J. (2014) New insights into the Hadean mantle revealed by ${ }^{182} \mathrm{~W}$ and highly siderophile element abundances of supracrustal rocks from the Nuvvuagittuq Greenstone Belt, Quebec, Canada. Chemical Geology 383, 63-75.

Touboul, M., PuChTEL, I.S., WALKER, R.J. (2015) Tungsten isotopic evidence for disproportional late accretion to the Earth and Moon. Nature 520, doi: 10.1038/nature14355.

WALKER, R.J. (2009) Highly siderophile elements in the Earth, Moon and Mars: Update and implications for planetary accretion and differentiation. Chemie der Erde - Geochemistry 69, 101-125.

Warren, P.H., UlfF-Møller, F., Huber, H., Kallemeyn, G.W. (2006) Siderophile geochemistry of ureilites: A record of early stages of planetesimal core formation. Geochimica et Cosmochimica Acta 70, 2104-2126. 
Willbold, M., ElLiOTt, T., Moorbath, S. (2011) The tungsten isotopic composition of the Earth's mantle before the terminal bombardment. Nature 477, 195-198.

Willbold, M., Mojzsis, S.J., Chen, H.-W., ElliotT, T. (2015) Tungsten isotope composition of the Acasta Gneiss Complex. Earth and Planetary Science Letters 419, 168-177.

YOKOYAMA, T., WALKER, R.J. (2016) Nucleosynthetic Isotope Variations of Siderophile and Chalcophile Elements in the Solar System. Reviews in Mineralogy and Geochemistry 81, 107-160.

Young, E.D., Manning, C.E., Schauble, E.A., Shahar, A., Macris, C.A., Lazar, C. JORDAN, M. (2015) High-temperature equilibrium isotope fractionation of non-traditional stable isotopes: Experiments, theory, and applications. Chemical Geology 395, 176-195. 